\title{
Adoption and Use of Educational Technology Tools by Marketing Students
}

\author{
José Magano ${ }^{1,2}$, Marta Alves ${ }^{3}$, Rita Durão ${ }^{3}$, and Carlos Vaz de Carvalho ${ }^{3}$ \\ ${ }^{1}$ Research Center in Business and Economics (CICEE), Universidade Autónoma de Lisboa, Portugal \\ ${ }^{2}$ ISCET - Higher Institute of Business Sciences and Tourism, Portugal \\ ${ }^{3}$ GILT, Instituto Superior de Engenharia do Politécnico do Porto, Portugal \\ jmagano@iscet.pt
}

DOI: 10.34190/EJEL.20.18.4.007

\begin{abstract}
Changing trends in educational technology are one of the driving forces behind many of the new educational strategies Higher Education Institutions are introducing. These changes are frequently justified with the "digital native" nature of the current generation of students who have been surrounded by digital technology from the moment they were born and are expected to also feel comfortable to use and adopt technological tools for their learning purposes. There have been many studies trying to assess the veracity of this assumption, but we still do not have enough data to confirm or deny this willingness and aptitude or even assess if students benefit from a technologically supported approach to learning. More studies are therefore necessary, in particular in subject areas that are not so connected to the technology, like humanities, economics, and social sciences, where students cannot be expected to be so proficient in the use of those tools and therefore their technology adoption process might be dependent of other variables. This article intends to contribute to this effort by presenting a study that uses the UTAUT model to assess which variables influence the use and adoption of educational technologies' tools by Higher Education Marketing students. The result showed that, for these students, Social Influence (or Social Factors) was the most relevant variable to determine their Behavioural Intention.
\end{abstract}

Keywords: educational technology; higher education; marketing; learning management systems; UTAUT

\section{Introduction}

Important achievements in different education-related areas like Cognitive Science, Psychology, User Experience, Digital Technology, etc., have contributed significantly to improvements in educational practices and as a consequence, traditional educational settings are no longer the unique approach to learn (Mota, Vaz de Carvalho and Reis, 2011). The omnipresent Internet generated the current connected society and made it easier to support different learning perspectives (for example, Cognitivism, Constructivism and Connectivism), different delivery approaches (namely, blended learning, online learning and Massive Open Online Courses, flipped classroom, adaptive learning) and in different contexts (formal, informal or non-formal) (Hanover Research, 2014). In Europe, the pressure to use technologies for learning emerged also from the implementation of the Bologna Declaration, which aimed to harmonize the structures of Higher Education (HE) and to increase the competitiveness of the European HE system. In that sense, it is clear that rethinking pedagogy and learning for the digital age is an actual theme revealing the importance of getting a proper understanding of both changes and challenges that educational environments are facing from an institutional point of view but also from the teachers' and students' perspectives (Mota, Vaz de Carvalho and Reis, 2014). In fact, new learning technology, tools and resources changed the way students access information and build their knowledge and somehow facilitated different approaches to learning by students with different needs and different learning styles, which resulted beneficial for teachers and learners. Different initiatives and projects were developed involving interactive web sites, learning applications, online training activities, intelligent tutoring environments and many others. Serious games have also been identified as excellent skill and competence development tools (Gouveia et al, 2014, pp 49-53).

Higher Education teachers are aware that the evolution of technology changed the way students build their knowledge. Nevertheless, more research has still to be conducted to fully understand how (and if) the students' interaction with the learning technologies relates to their learning success. In fact, technology enhanced learning can be underpinned by many different pedagogical approaches, some of which can be more successful than others (Persico et al., 1997), so there is no single, match-all, solution for this question.

This is particularly relevant in subject domains which are not so close to technology like Humanities, Economics, Social Sciences, etc. where students cannot be expected to be so proficient in the use of those tools. It is therefore important to understand what variables condition the adoption and use of these tools by these students. The case of Marketing education, particularly at the tertiary level, is one clear case of this situation 
where the use of the new educational technologies has been accepted and promoted as both inevitable and beneficial but where the potential negative aspects of this integration might have been somehow overlooked. McCorkle, Alexander and Reardon (2001) mentioned that "Technology is transforming the way businesses use marketing, the way marketing educators teach students, and the way students learn marketing". Celsi and Wolfinbarger (2001) said that marketing education moved through three stages of technological pedagogy, and, at the time, was in its third stage, "characterized by unique technological applications that extend the classroom to become a more current, active, and interactive learning environment". Buzzard et al. (2011) provided some examples of the integration of technology in marketing education in the classroom perspective. These studies cover a broad spectrum of the use of educational technologies, from the traditional digital slide usage in the classroom (Peterson, et al., 2002; Ferrel and Ferrel, 2002) to the use of online tools like wikis (Cronin, 2009; Workman, 2008), assessment tools (Debuse and Lawley, 2011), virtual environments like Second Life (Hu, 2009; Newman and Hermans, 2008; Wood, Solomon and Allan, 2008; Tuten, 2009), social media (Tuten and Marks, 2012; Khan, 2013; Faulds and Mangold, 2014; Crittenden and Crittenden, 2015) and smartphones (Caruso and Salaway, 2007; Bal et al., 2010). In general, these studies report positive effects on student motivation and learning but they are mostly casuistic and do not portrait a systematic use of the technology. In fact, the more interesting studies reported by Buzzard relate to the positive effects of the correlation between intrinsic personal variables like performance expectation and attitude towards technology and the achieved results. That is the case of Robinson (2006), Hunt, Eagle and Kitchen (2004) and Strauss (2007). In the last study, the most relevant aspect actually related to the fact that almost one half of the students were not interested in the use of technology as it (perceptually) demanded too much time and energy in comparison to the traditional classroom model.

One type of educational technology tools that have become standard are Learning Management Systems. Like in the other subject areas, Marketing courses are turning to these tools to support the delivery of courses in different formats. For the teachers it is important to understand how these platforms function to follow the current trend as the delivery of marketing education is rapidly shifting toward a pedagogy rich in experiential learning and strongly supported with educational technology. For the students, it is an opportunity to improve their digital literacy and become experienced in the use of online platforms that include functionalities (synchronous and asynchronous communication and collaboration, workflow, task management, community management, etc.) that are also frequently used in the context of professional activities.

This article examines this issue from the point of view of Technology Adoption processes, namely through the Unified Theory of Acceptance and Use of Technology (UTAUT) model. Research findings captured in the scope of a Higher Education Marketing semester programme are presented to show how students effectively respond to the new technological modes of teaching.

\section{The UTAUT - Unified Theory of Acceptance and Use of Technology}

The Unified Theory of Acceptance and Use of Technology normally abbreviated to its acronym UTAUT represents a synthesis of eight previous models of technology acceptance and use:

- Theory of Reasoned Action (TRA): this theory proposed by Fishbein and Ajzen (1975) intended to predict the behaviour of users in a given situation. Its main premise considered that users would adopt a specific behaviour if they perceived that it would lead to positive results. In the TRA, a person's behaviour is directly influenced by his/her willingness to adopt or not that behaviour. This Behavioural Intention is influenced by two factors: Attitude Towards the Behaviour and Subjective Norm;

- Technology Acceptance Model (TAM): this theory was specifically designed for the area of Information Technology and it was successfully tested and applied by several researchers like Persico, D., Manca, S. and Pozzi (2014). TAM included measures related to technology acceptance, namely the ease and usefulness of a system and the Behavioural Intention to Use, which represented the users' willingness to use the system as determined by two variables: Perceived Ease of Use and Perceived Usefulness (Davis, 1989).

- Motivation Model (MM): In this model motivational variables, such as promotion, management and regulation of behaviour were a core component of the motivational activation process in the pedagogical intervention. In fact, the intentional processes that streamlined the construction of the users' psychosocial identity required a broad understanding of some pre and post decisional processes underlying the functioning of personalized motivation in meaningful contexts of interaction, examples 
of which are the self-efficacy expectations, perceptions of barriers within the scope of socio professional performance, and personal achievements of planned actions (Bandura, 1993);

- The Theory of Motivation: formulated by Deci (1985) defended that the behaviour was determined by intrinsic and extrinsic motivations. While extrinsic motivations lead to action because of its potential rewards such as increased performance, intrinsic motivations refers to the satisfaction resulting from the actual practice of the action. Vroom applied this theory to the study of the adoption and use of new IT in business contexts (Isaac, Zerbe and Pitt, 2001);

- $\quad$ Theory of Planned Behaviour (TPB): TPB was an extension of the TRA that added the variable Perceived Behavioural Control, defined as the perception of a person on the ease or difficulty on the practice of a particular behaviour. The Perceived Behavioural Control depends on Control Beliefs and Perceived Facilitation of that control factor to facilitate or inhibit behaviour (Ajzen, 1991);

- Combined Model TAM/TPB (TAM/TPB): Taylor and Todd (1995) introduced a hybrid model that combined the variables of the TPB with the Perceived Usefulness of the TAM. They added a variable on the user IT experience, called Previous Experience. Taylor and Todd theorized that by separating users into groups based on Previous Experience, different forces would be revealed on the effects of variables of this model. For new users, the Behavioural Intention seemed to be more influenced by the Perceived Usefulness, followed by the Ease of Use. The main contribution of this combined model suggested that the experience levels of users should be considered in studies of the acceptance of IT;

- Model of PC Utilization (MPCU): MPCU was based on the Theory of Human Behaviour established by Triandis (1977). Some authors adapted this theory to predict the actual use of personal computers rather than the intention of use. The scope of its application has been now enlarged to predict the acceptance of a wide variety of IT;

- Innovation Diffusion Theory (IDT): IDT was based on a Sociology approach to explain the use and adoption of technology (Rogers, 1962). The concept of innovation was presented as an idea, practice, or object that was perceived as something new for a user. Innovation creates uncertainty, which motivates a user to seek information about alternatives. Diffusion is the process by which innovation is communicated over time through different channels by the members of a social system. IDT aimed to explain the decision process of innovation and to determine the factors that influenced the rate of adoption as well as the adopter's categories. It also aimed to predict the probability of adoption of an innovation and its adoption rate. One of the most important contributions of this theory was the definition of the innovation-decision process, which begins with the users' acknowledgment of innovation and ends with the confirmation of the adoption or rejection of that innovation;

- Social Cognitive Theory (SCT): SCT supported the search for answers to questions such as: how relevant are work and other life roles? How can individuals take self-directivity in their development progress?

- The initial Bandura's social learning theory emphasized the personal variables of self-efficacy, outcome expectations, goals and interaction with environmental variables such as the importance of personal development and social support. Bandura (1986) assumed that a complex set of factors - culture, gender, socio-structure, state of health - worked together and influenced the cognitions, the nature and scope of skills. As such this theory could scaffold the individual and specific behaviour in relation to technology adoption.

\subsection{Unified Theory of Acceptance and Use of Technology - UTAUT}

UTAUT was published by Venkatesh et al. (2003) based on empirical and conceptual similarities of the eight models/theories presented previously and having as goal, as the name indicates, to unify all those models. Authors empirically compared the models in four organizations of different industries that had plans to introduce new technological systems. Two of these systems were of compulsory use and two of the others were voluntary. They conducted longitudinal studies on three different occasions: after the training but before using the system, a month after starting to use the system and three months after the system implementation. The level of system use was finally measured six months after the training of users. The model was then validated in two other organizations, explaining approximately $70 \%$ of the variation in technology acceptance behaviour, a notable increase over other models that, on average, stood at $40 \%$.

The UTAUT model proposed three variables that determined, directly and significantly, the Behavioural Intention of using a particular system, namely: Performance Expectancy, Effort Expectancy and Social Influence (also known as Social Factors). Therefore, Behavioural Intention is the willingness shown by the user in using the system in the future. A fourth variable, Facilitating Conditions, influence directly the Use Behaviour, which 
concerns the effective use of the system. As moderators of those variables there are four other variables: Gender, Age, Years of Experience and Voluntariness (or Willingness) of Use as can be seen in Figure 1.

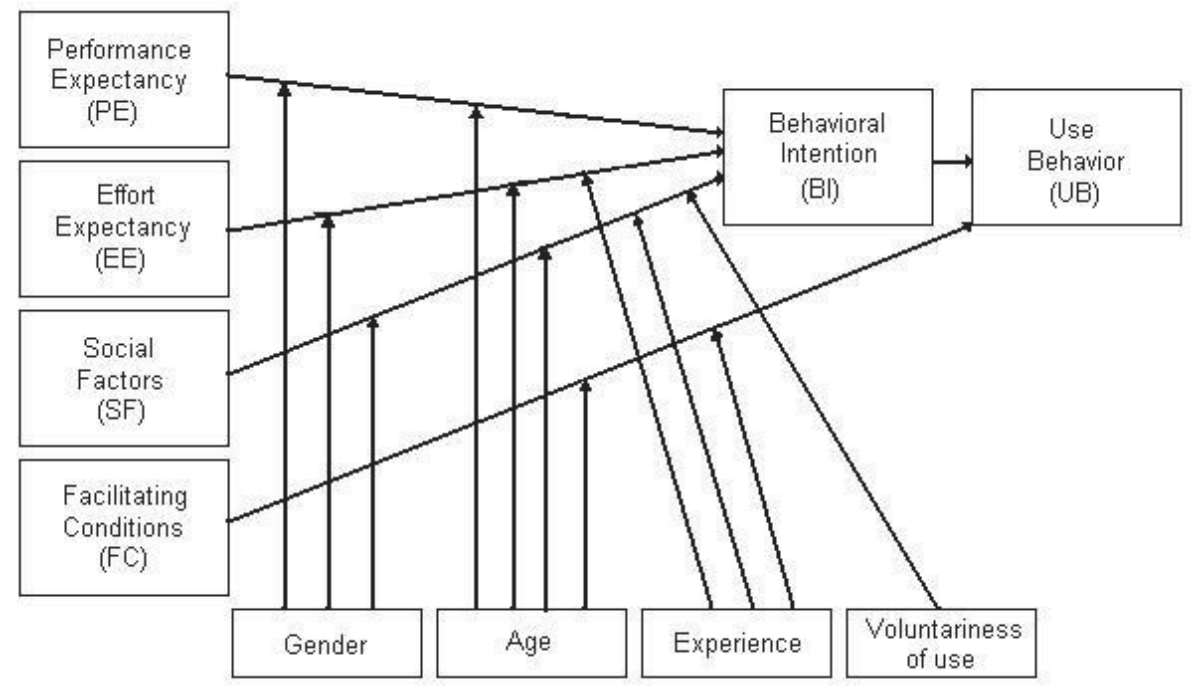

Figure 1: Graphical representation of UTAUT Model (Venkatesh et al., 2003)

In summary, as independent variables in this model, we have:

- Performance Expectancy (PE), defined as the degree to which the user believes that using a particular system will improve his/her performance. This variable, independently of a voluntary or mandatory use of the system, is the strongest determinant for the prediction of Behavioural Intention (BI). The relationship between Performance Expectancy and $\mathrm{Bl}$ is moderated by Gender and Age;

- Effort Expectancy (EE) refers to how easy the use of a certain system will be, as perceived by the user. It is a significant variable, both within the voluntary and mandatory use of a system. The Effort Expectancy is moderated by Gender, Age and Years of Experience in relation to BI;

- Social Influence (SI) or Social Factors are defined as the degree to which a user perceives how important it is for other people that they use the system. This variable is based on the assumption that individual behaviour is influenced by the way a user believes other people will look at him/her according to whether he/she uses the technology. The moderators of Social Influence are: Years of Experience, Gender and Age.

- Facilitating Conditions (FC): Facilitating conditions are defined as the degree to which a user believes that an organizational and technical infrastructure exist to support the system. Facilitating conditions have a direct influence on Use Behaviour and are moderated by Years of Experience and Age.

\section{Assessing Marketing Students Acceptance and Use of Technology}

Hollenbeck, Mason and Song (2011) propose that the five fundamental pedagogical principles for enhancing student learning through the use of technology are: a) student-to-student connectivity, b) instructor-to-student interactivity, c) goal efficiency, d) quality content, and e) student appeal.

It is clear that, as mentioned before, digital technologies made an impact on all aspects of society over recent years, and its potential to transform education is directly related to its impact in the pedagogical principles presented earlier. But it is not sufficiently evidenced that students do prefer a pedagogical model based on technology for effective engagement and learning. Moreover, this does not depend only on the students, as there are other external aspects involved like the institutional strategy, the teacher proficiency in educational technology (which might condition the motivational and immersiveness of the created digital environment), and the technological support itself. So, educational technology needs to be adopted by educational managers, teachers and students to achieve its full efficiency. According to Peterson et al (2002), "any new instructional technology should allow a student to learn more, learn faster, and/or learn easier". D'Aloisio (2006) therefore proposes that if students perceive a correlation between the skills they acquire in the classroom and the transferability of those skills to their future professional career, they will be more motivated to participate actively in their education. Those skills might include instructional technologies as a skill set for the future. 
As such, this study captured technology usage from the perspectives of students and, in doing so, related instructional technologies to the student engagement in the course/subject. The study was conducted between March (T1) and June (T2) of 2018, involving marketing students of ISCET, a Higher Education Institution in Northern Portugal. The aim was to understand how students related to and adopted educational technologies. The survey was based on an online questionnaire, using the UTAUT model, to which 101 students responded in March, and then again in June of 2018.

The whole process begun by asking students to answer a survey in March 2018 (T1). This happened right before challenging four teachers to change their educational practices and to adopt a technology-based approach to their teaching. A flipped-classroom approach was selected, and teachers created specific educational contents, such as video-lectures, notes, animated/video tutorials, and self-assessment quizzes, which were made available online through the institutional LMS platform (Moodle). The main purpose was to foster an active learning approach by students where they could study online contents prior to class lectures which were mostly for discussion and application of those concepts and also use the LMS to review the concepts afterwards and to continue the classroom discussion through the online tools. At first, students reacted positively, though they didn't show particular excitement. Throughout the process, for three months, the platform statistics showed that only part of the students actually accessed viewed the online content with video tutorials recording the most hits. During the semester an increasing number of students accessed part of the contents and was able to debate them in class.

During class lectures, teachers kept reminding their students about new published contents, and introduced some gamification elements like Kahoot quizzes. This approach led students to include their smartphones in the learning process, connecting them to the LMS, stimulating their attention and increasing the effective participation in learning activities. The intent of such actions was to create a more exciting and engaging learning atmosphere, and to increase the students' perception of instructional technology use.

At the end of the study period, by middle June 2018 (T2), the second stage of the survey was implemented, by asking students to answer the same questionnaire they had answered to three months earlier.

The questionnaire items used to measure the different UTAUT variables were:

Performance Expectancy (PE)

PE1 - I find the system useful for the course.

PE2 - Using the system will enable me to accomplish tasks more quickly.

PE3 - Using the system will increase my productivity.

PE4 - If I use the system, I will increase my chances of getting a high grade.

Effort Expectancy (EE)

EE1 - My interaction with the system will be clear and understandable.

EE2 - It will be easy for me to become skilful at using the system.

EE3 - I find the system easy to use.

EE4 - Learning to operate the system is easy for me.

Attitude Toward Using Technology (ATUT)

ATUT1 - Using the system is a good idea.

ATUT 2 - The system will make work more interesting.

ATUT 3 - Working with the system is fun.

ATUT 4 - I like working with the system.

Social Influence (SI)

SI1 - People who are important to me think that I should use the system.

SI2 - People who influence my behaviour think that I should use the system.

SI3 - The instructor of this course has been helpful in the use of the system.

SI4 - In general, the university has supported the use of the system.

Facilitating Conditions (FC)

FC1 - I have the resources necessary to use the system.

FC2 - The system is not compatible with other systems I use.

FC3 - I have the knowledge necessary to use the system.

FC4 - A specific person (or group) is available for assistance with system difficulties.

Self-Efficacy (SE)

SE1 - I could complete a job or task using the system... 
SE2 - If there was no one around to tell me what to do as I go.

SE3 - If I could call someone for help if I got stuck.

SE4 - If I had a lot of time to complete the job for which the software was provided.

SE5 - If I had just the built-in help facility or assistance.

Anxiety (ANX)

AN1 - I hesitate to use the system for fear of making mistakes I cannot correct.

AN2 - It scares me to think that I could lose a lot of information using the system by hitting the wrong key.

AN3 - I feel apprehensive (anxious) about using the system.

AN4 - The system is somewhat intimidating to me.

Behavioural Intention to use the system (BI)

BI1 - I plan to use the system in the next 4 months.

BI2 - I predict I would use the system in the next 4 months.

$\mathrm{BI} 3$ - I intend to use the system in the next 4 months.

Use Behaviour (UB)

TEC_USE1 I have used the system a lot in the past 4 months.

TEC_USE2 I have been using the system regularly in the past 4 months.

Other moderating factors - Gender, Age and Years of Experience (YE)- were collected also in the questionnaire.

\section{Results}

With this study, authors wanted to assess if the UTAUT model could provide an effective answer that explained the behaviour of students. In particular, and after the teachers' observation during the semester having revealed lack of use of the tools, it was expected that results would provide clues to improve its adoption.

Using a two-sided test, $5 \%$ significance level test $(\alpha=0.05)$ with power $80 \%$ power $(\beta=0.2)$, the required sample size is approximate 95 for correlations (Venables and Ripley, 2013). For regression, significance level test $(\alpha=0.05)$ with power $80 \%$ power $(\beta=0.2)$, the required sample size is approximately 102 (Jenkins, 2020), which is not far from the sample of 101.

To validate the questionnaires, the internal consistency reliability (ICR) was calculated using Cronbach's Alpha for each construct in each time period (T1 and T2) as shown in Table 1. All constructs had an ICR higher than 0.7 except Technology Use (T1), Social Influence (T2) and Self Efficacy in T1 and T2. High ICR indicates that the items used to measure that construct are adequately representing the construct and generate similar scores. Despite the below threshold ICR values for SI and SE, they were not dropped from the model because the values were still high and due to their importance in the original model. Additionally, a correlation matrix (Table 2) showed that inter-construct correlations were generally low.

Table 1: ICR measured by Cronbach's Alpha

\begin{tabular}{lcc} 
& \multicolumn{2}{c}{ Cronbach's Alpha } \\
\cline { 2 - 3 } TEC_USE & T1 & T2 \\
\cline { 2 - 3 } PE & $0,760^{*}$ & $0,625$. \\
EE & $0,848^{* *}$ & $0,883^{* *}$ \\
ATUT & $0,826^{* *}$ & $0,884^{* *}$ \\
SI & $0,857^{* *}$ & $0,901^{* * *}$ \\
SE & $0,676$. & $0,724 *$ \\
FC & 0,567 & 0,557 \\
ANX & $0,681$. & $0,817^{* *}$ \\
BI & $0,860 * *$ & $0,873^{* *}$ \\
\hline
\end{tabular}


Table 2: Correlation matrix

\begin{tabular}{r|rrrrrrrrr} 
& TEC_USE & PE & EE & ATUT & SI & FC & SE & ANX & BI \\
\hline TEC_USE & 1.0000 & & & & & & & & \\
PE & 0.1943 & 1.0000 & & & & & & & \\
EE & 0.1886 & 0.4633 & 1.0000 & & & & & & \\
ATUT & 0.1167 & 0.5969 & 0.5872 & 1.0000 & & & & & \\
SI & 0.0534 & 0.4739 & 0.5044 & 0.5608 & 1.0000 & & & & \\
FC & 0.1033 & 0.4863 & 0.5749 & 0.5957 & 0.4926 & 1.0000 & & & \\
SE & 0.0417 & 0.3792 & 0.3135 & 0.3655 & 0.2415 & 0.4838 & 1.0000 & & \\
ANX & 0.0286 & -0.0486 & -0.1296 & -0.1194 & 0.0430 & -0.1132 & -0.0915 & 1.0000 & \\
BI & 0.0698 & 0.5093 & 0.5738 & 0.5785 & 0.6177 & 0.5621 & 0.3869 & -0.0592 & 1.0000
\end{tabular}

Technology acceptance was measured by the Behavioural Intention (BI) of using the technology. Like in the original UTAUT study, the effect of the direct predictor variables on intention was measured for each time period (T1 and T2) and for the pooled data across time periods. The results of the analysis are summarized in Table 3. Linear regression was used to regress Behavioural Intention on the predicting variables and the moderating variables.

Table 3: Regression Results

Dependent Variable: Behavioural Intention

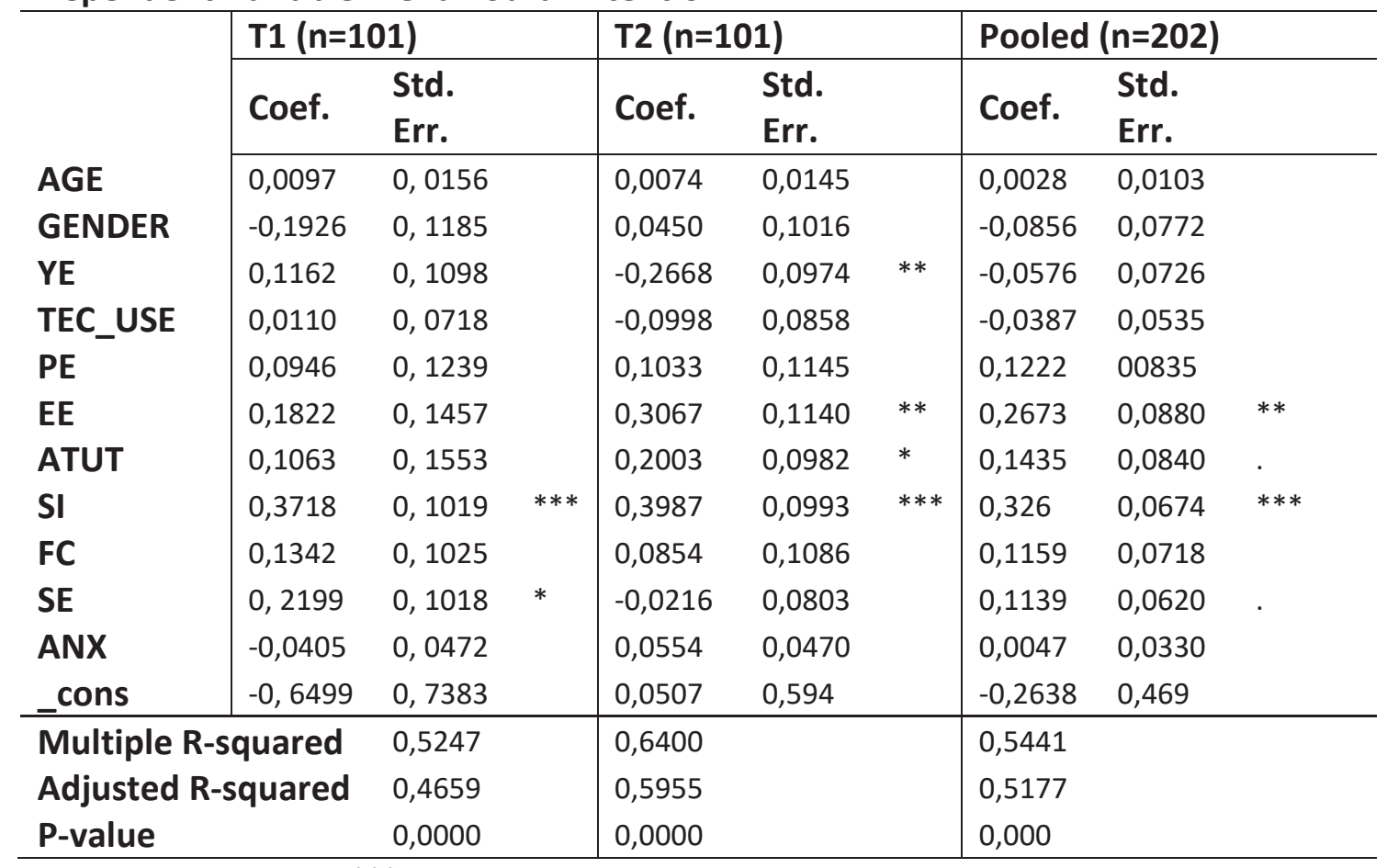

Note: Significance codes: $>0 * * *>0,01 * *>0,05 *>0,1$

\section{Results}

The results obtained from the study could lead to mixed interpretations. Firstly, most of the variables were not found to have a significant effect in Behavioural Intention Social Influence (or Social Factors) had the strongest effect which might be due to the age of the participants and their expectation that teachers wanted them to use the technology. Peer pressure could have also had a role here as some group work was conducted online so not using the tools might have been perceived as not contributing to the work.

Effort Expectancy had a significant influence on Behavioural Intention but mostly in T2 and on the pooled data. Students might have been somehow reluctant in the use of the tools in a first moment due to an anticipated greater effort and finally after realizing that the level of required work was after all equivalent to the other courses with traditional pedagogical methodologies their EE was better adjusted. Self-Efficacy and Attitude 
Towards Using Technology also had some effect in the Behavioural Intention. The reason behind this might be that students were less confident with the system when they were introduced to it, but with increased experience this effect disappeared. Facilitating Conditions had no significant influence on Behavioural Intention probably because students used the tools mostly at home and the organizational support was mostly related to ensuring that the system as available (online). Curiously, the actual Use Behaviour had no strong correlation with Behavioural Intention which might be connected to a change in the use pattern during the semester

\section{Conclusions}

The introduction of educational technology in Marketing education like in the other academic domains has been seen as a requirement to attract and motivate students who have been surrounded by digital technology from the moment they were born. However, this is not a straightforward assumption as in many cases technology ends up being a distractor rather than an enabler. It is therefore important to understand what are the variables that can contribute to the adoption of technology by students for their academic purposes particularly in subject areas that are not so connected to technology. This study contributed to this effort by using the UTAUT technology adoption model to establish if students do relate to educational technologies when they are requested to use them in the scope of a Marketing course with a different pedagogical approach (flipped classroom) relying on those technologies. For that purpose, a study was organized during a semester of a Higher Education programme in Marketing, using a sample of 101 students. Although the sample size was a limitation of the work, a very interesting finding was that Social Influence had a significant moderating effect on Behavioural Intention and Effort Expectancy was also a significant predictor. The model showed that, for these students, the use of technology was very much dependent on social factors and influence and effort expectancy. So, although that does not necessarily translate directly in actual use, it seems that the teacher, as a social influencer, still has a substantial role in the student's decision to use educational technologies.

\section{References}

Ajzen, I., 1991. The theory of planned behavior, Organizational behavior and human decision processes. San Diego, 50(2), pp. 179-211.

Bal, A. et al., 2010. Second best in Second Life: teaching marketing cases in a virtual world environment, in Proceedings of the 2010 Academy of Marketing Science (AMS) Annual Conference. Springer International Publishing, p. 211. doi: 10.1007/978-3-319-11797-3_119.

Bandura, A., 1986. Social foundations of thought and action: a social cognitive theory, Englewood Cliffs, N.J.: Prentice-Hall

Bandura, A., 1993. Perceived Self-Efficacy in Cognitive Development and Functioning. Educational Psychology. 28, 117-148. doi: $10.1207 /$ s15326985ep2802_3

Buzzard, C. et al., 2011. The Use of Digital Technologies in the Classroom: A Teaching and Learning Perspective, Journal of Marketing Education, 33(2), pp. 131-139. doi: 10.1177/0273475311410845.

Caruso, J. B. and Salaway, G., 2007. The ECAR study of undergraduate students and information technology, 2007. Available at: http://www.csplacement.com/downloads/ECAR-ITSkliisstudy.pdf (Accessed: 15 May 2020).

Celsi, R. and Wolfinbarger, M., 2001. Creating Renaissance employees in an era of convergence between information technology and business strategy: a proposal for business schools, Journal of Education for Business. Taylor \& Francis Ltd, 76(6), pp. 308-312. doi: 10.1080/08832320109599654.

Cronin, J. J., 2009. Upgrading to web 2.0: an experiential project to build a marketing wiki, Journal of Marketing Education, 31(1), pp. 66-75. doi: 10.1177/0273475308329250.

D'Aloisio, A., 2006. Motivating students through the awareness of the natural correlation between college learning and corporate work settings, College Teaching, 54(2), pp. 225-229. doi: 10.3200/CTCH.54.2.225-230.

Debuse, J.C.W., and Lawley, M., 2011. Using innovative technology to develop sustainable assessment practices in marketing education. Journal of Marketing Education, 33, 160-170

Deci, E. L. and Ryan, R. M., 1985. Intrinsic motivation and self-determination in human behaviour, Intrinsic Motivation and Self-Determination in Human Behavior. Springer US.

Ferrell, O. C. and Ferrell, L., 2002. Assessing instructional technology in the classroom, Marketing Education Review, 12(3), pp. 19-24. doi: 10.1080/10528008.2002.11488796.

Fishbein, M. and Azjen, I., 1985. Belief, attitude, intention and behaviour: an introduction to theory and research. AddisonWesley.

Gouveia, D., Andrade, A., Escudeiro, P. and Vaz de Carvalho, C., 2014. Skill and Competence Development Through Games, Proceedings of the 16th International Conference on Information Integration and Web-based Applications \& Services, pp. 49-53. doi: $10.1145 / 2684200.2684350$.

Bandura, A., 1986. Social foundations of thought and action: a social cognitive theory. 2nd edn. Prentice-Hall (Prentice-Hall series in social learning theory).

Buzzard, C. et al., 2011. The Use of Digital Technologies in the Classroom: A Teaching and Learning Perspective, Journal of Marketing Education, 33(2), pp. 131-139. doi: 10.1177/0273475311410845. 
Caruso, J. B. and Salaway, G., 2007. The ECAR study of undergraduate students and information technology, 2007. Available at: http://www.csplacement.com/downloads/ECAR-ITSkliisstudy.pdf (Accessed: 15 May 2020).

Celsi, R. and Wolfinbarger, M., 2001. Creating Renaissance employees in an era of convergence between information technology and business strategy: a proposal for business schools, Journal of Education for Business. Taylor \& Francis Ltd, 76(6), pp. 308-312. doi: 10.1080/08832320109599654.

Crittenden, V., and Crittenden, W., 2015. Digital and Social Media Marketing in Business Education: Implications for the Marketing Curriculum', Journal of Marketing Education, 37(2), pp. 71-75.

Cronin, J. J., 2009. Upgrading to web 2.0: an experiential project to build a marketing wiki, Journal of Marketing Education, 31(1), pp. 66-75. doi: 10.1177/0273475308329250.

D'Aloisio, A., 2006. Motivating students through the awareness of the natural correlation between college learning and corporate work settings, College Teaching, 54(2), pp. 225-229. doi: 10.3200/CTCH.54.2.225-230.

Deci, E. L. and Ryan, R. M., 1985. Intrinsic motivation and self-determination in human behaviour, Intrinsic Motivation and Self-Determination in Human Behavior. Springer US.

Faulds, D.J., and Mangold, W.G., 2014. Developing a social media and marketing course, Marketing Education Review, 24, 127-144.

Ferrell, O. C. and Ferrell, L., 2002. Assessing instructional technology in the classroom', Marketing Education Review, 12(3), pp. 19-24. doi: 10.1080/10528008.2002.11488796.

Fishbein, M. and Azjen, I., 1985. Belief, attitude, intention and behaviour: an introduction to theory and research. AddisonWesley.

Hanover Research, 2014. Trends in higher education marketing, recruitment, and technology. Available at: https://www.hanoverresearch.com/media/Trends-in-Higher-Education-Marketing-Recruitment-and-Technology2.pdf (Accessed: 15 May 2020).

Hollenbeck, C. R., Mason, C. H. and Song, J. H., 2011. Enhancing student learning in marketing courses: an exploration of fundamental principles for website platforms, Journal of Marketing Education, 33(2), pp. 171-182. doi: 10.1177/0273475311410850.

$\mathrm{Hu}, \mathrm{H} ., 2$ 2009. An international virtual team based project at undergraduate level: design and assessment , Marketing Education Review, 19(1), pp. 17-22. doi: 10.1080/10528008.2009.11489055.

Hunt, L., Eagle, L. and Kitchen, P. J., 2004. Balancing marketing education and information technology: matching needs or needing a better match?', Journal of Marketing Education, 26(1), pp. 75-88. doi: 10.1177/0273475303262350.

Isaac, R. G., Zerbe, W. J. and Pitt, D. C., 2001. Leadership and motivation: the effective application of expectancy theory', Journal of Managerial Issues, 13(2), pp. 212-226.

Jenkins, D. G. and Quintana-Ascencio, P. F., 2020. A solution to minimum sample size for regressions. PloS One 15(2):e0229345. doi.org/10.1371/journal.pone.0229345Khan, R.H., 2013. Marketing Education Online: A Case study of New Zealand Higher Education Institutions, Procedia-Social and Behavioral Sciences, 103 (2013), pp. $637-646$.

McCorkle, D. E., Alexander, J. F. and Reardon, J., 2001. Integrating business technology and marketing education: enhancing the diffusion process through technology champions', Journal of Marketing Education. SAGE Publications Inc, 23(1), pp. 16-24. doi: 10.1177/0273475301231003.

Mota, D., Reis, L. P. and Carvalho, C. V. de, 2014. Design of learning activities - pedagogy, technology and delivery trends', EAI Endorsed Transactions on e-Learning, 1(4), pp. 1-11. doi: 10.4108/el.1.4.e5.

Mota, D., Vaz de Carvalho, C. and Reis, L. P., 2011. Fostering collaborative work between educators in higher education, in 2011 IEEE International Conference on Systems, Man, and Cybernetics, Systems, Man, and Cybernetics (SMC), 2011 IEEE International Conference, pp. 1286-1291. doi: 10.1109/ICSMC.2011.6083837.

Newman, A. J. and Hermans, C. M., 2008. Breaking the MBA delivery mould: A virtual international multi-group MBA/ practitioner collaborative project, Marketing Education Review, 18(1), pp. 9-14. doi: 10.1080/10528008.2008.11489018.

Persico D., 1997. Methodological constants in courseware design. British Journal of Educational Technology, 28 (2), pp. 111-124, DOI: 10.1111/1467-8535.00015.

Persico, D., Manca, S. and Pozzi, F., 2014. Adapting the technology acceptance model to evaluate the innovative potential of e-learning systems, Computers in Human Behavior. doi: 10.1016/j.chb.2013.07.045.

Peterson, R. A. et al., 2002. Reflections on the use of instructional technologies in marketing education, Marketing Education Review, 12(3), pp. 7-17. doi: 10.1080/10528008.2002.11488795.

Robinson, L. J., 2006. Moving beyond adoption: exploring the determinants of student intention to use technology, Marketing Education Review, 16(2), pp. 79-88. doi: 10.1080/10528008.2006.11488962.

Rogers, E. M., 1962. Diffusion of innovations. New York: Free Press of Glencoe.

Strauss, J. and Hill, D. J., 2007. Student use and perceptions of web-based instructional tools: laggards in traditional classrooms, Marketing Education Review, 17(3), pp. 65-79. doi: 10.1080/10528008.2007.11489014.

Taylor, S. and Todd, P., 1995. Assessing IT usage: the role of prior experience, MIS Quarterly, 19(4), pp. 561-570. doi: $10.2307 / 249633$.

Triandis, H. C., 1977. Interpersonal behavior. Brooks/Cole Pub. Co.

Tuten, T., 2009. Real world experience, virtual world environment: The design and execution of marketing plans in Second Life', Marketing Education Review, 19(1), pp. 1-5. doi: 10.1080/10528008.2009.11489053. 
Tuten, T., and Marks, M., 2012), The adoption of social media as educational technology among marketing educators. Marketing Education Review, 22(3), 201-214.

Venables, W. N., and Ripley, B. D., 2013. Modern pplied statistics with S-PLUS. New York: Springer Science \& Business Media.

Venkatesh, V. et al., 2003. User acceptance of information technology: toward a unified view, MIS Quarterly, 27(3), pp. 425-478. doi: 10.2307/30036540.

Wood, N. T., Solomon, M. R. and Allan, D., 2008. Welcome to the matrix: e-learning gets a Second Life', Marketing Education Review, 18(2), pp. 47-53. doi: 10.1080/10528008.2008.11489037.

Workman, J. P. J., 2008. Wikis in the classroom: opportunities and challenges', Marketing Education Review, 18(1), pp. 1924. doi: $10.1080 / 10528008.2008 .11489020$. 